\title{
UN goals trigger calls for reforming Canadian aid
}

A set of Sustainable Development Goals (SDGs) adopted by the United Nations will require Ottawa to extensively reform its international aid strategies, global health experts warn.

The 17 SDGs specify 169 targets, including ambitious goals to dramatically reduce child and maternal mortality, ensure universal access to sexual and reproductive health care services including family planning, and eradicate epidemics of HIV/AIDS, malaria and tuberculosis, all by 2030 .

The new goals, which come into effect Jan. 1, 2016, are a "roadmap to ending global poverty," according to United Nations Secretary-General Ban Ki-moon.

Although Canada, with 192 other nations, has agreed to support the SDGs, many of its development strategies are out of step with them, said Janet Hatcher Roberts, co-director of the World Health Organization Collaborating Center for Knowledge Translation and Health Technology Assessment for Health Equity at the University of Ottawa.

"If we're serious about our commitment to the SDGs, we'll have to stop slashing development spending and recommit to international programs including education and environmental sustainability," Hatcher Roberts said.

She notes that from 2010 to 2014 , Canadian aid budgets were cut almost $20 \%$ (from $0.34 \%$ to $0.27 \%$ of gross domestic product). And although Canada's funding for maternal and child health increased by $\$ 146$ million annually during this period, spending on education was cut by $\$ 166$ million annually. The SDGs strongly emphasize that health and education are interlinked.

Ottawa is especially out of step with the SDG pledge to "ensure universal access to sexual and reproductive health care services, including for family planning, information and education, and the integration of reproductive health into national strategies and programs," said Sandeep Prasad, executive director of the pro-choice charity Action Canada for Sexual Health and Rights.

Prasad notes that Canada's maternal and child health programs currently

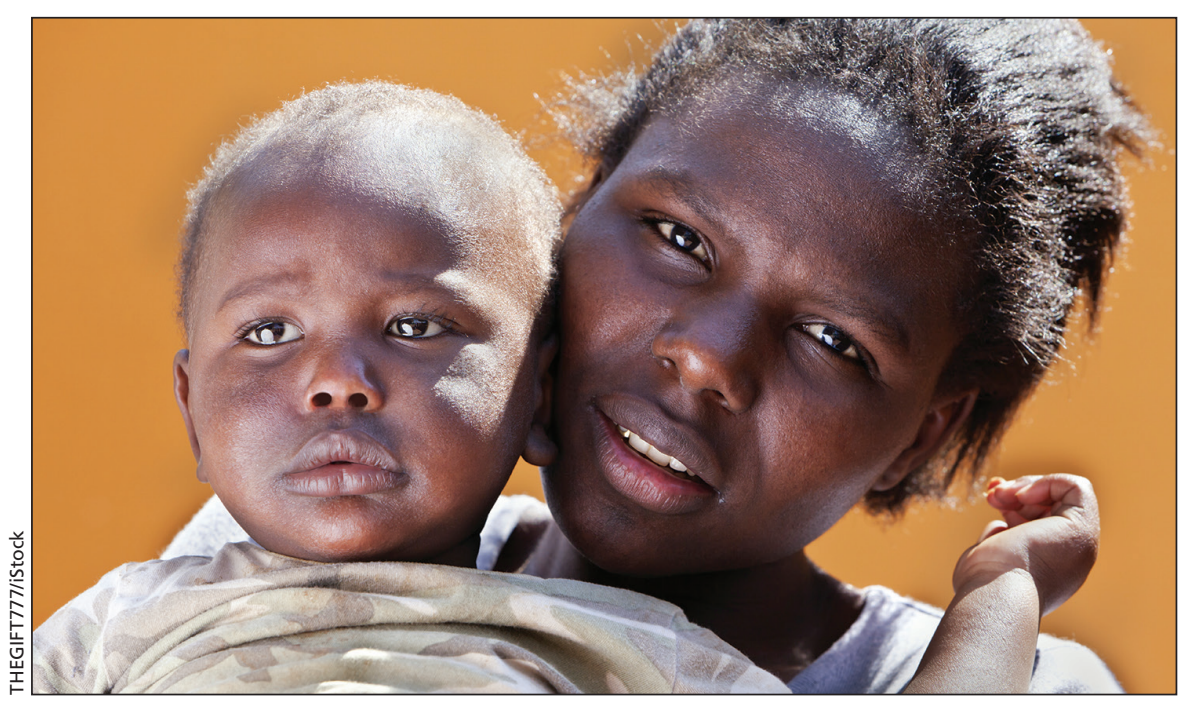

New UN Sustainable Development Goals commit Canada to supporting access to abortion and contraception.

exclude funding for services that provide women with access to abortion, while "ignoring" services that provide access to contraception.

"There's no doubt the SDGs commit Canada to supporting access to abortion and contraception, along with a broader array of sexual health services," said Prasad.

The Canadian Network for Maternal, Newborn and Child Health (CAN$\mathrm{MNCH}$ ) has received $\$ 1.8$ million from Ottawa to help the government develop science-based maternal and child health programs overseas, and promote public understanding of Canada's efforts at home. CAN-MNCH Director Helen Scott declined to be interviewed about the implications of the SDGs, citing the Oct. 19 federal election.

Dr. Jennifer Brenner, who is a member of CAN-MNCH's "measuring results" working group and Canadian director of Healthy Child Uganda, a Calgary-based aid project, notes that the illegality of abortion in Uganda is a "big issue" when it comes to tackling maternal and child health. Reproductive health services "have definitely got to be part of the package," she said.

The emphasis on integrated approaches to global health within the SDGs is encouraging, said Brenner. The goal to reduce global maternal mortality to less than 70 per 100000 live births from 230 is achievable only with approaches that integrate health, education and social programs.

Dr. Zulfiqar Bhutta, who holds the Robert Harding Inaugural Chair in Global Child Health and Policy at The Hospital for Sick Children in Toronto, agrees with Brenner that the SDG goal for maternal health can be achieved only if financial commitments are greatly increased by wealthy nations.

Bhutta also believes the SDG target of reducing neonatal mortality to at least as low as 12 per 1000 live births and under-five mortality to at least as low as 25 per 1000 live births by 2030, is doable with increased financial commitments.

The 2000 SDG targets helped deliver substantial progress against infectious diseases and dramatic reductions in child and maternal deaths. The global neonatal mortality rate fell from 36 deaths per 1000 live births in 1990 to 19 in 2015. The global under-five mortality rate dropped 53\%, from 91 deaths per 1000 live births in 1990 to 43 in 2015, according to the UN Inter-agency Group for Child Mortality Estimation.

"Canada has stood firm with its commitments to maternal and child health," Bhutta said after noting that other wealthy nations have slashed their commitments. "But even so, we will face considerable financial challenges." Paul Christopher Webster, Toronto, Ont.

CMAJ 2015. DOI:10.1503/cmaj.109-5167 